\title{
Special issue on semantic ambient media experience
}

\author{
Artur Lugmayr • Thomas Risse • Bjoern Stockleben • \\ Juha Kaario • Kari Laurila
}

Published online: 6 May 2009

(C) Springer Science + Business Media, LLC 2009

\section{Introduction}

It is our great pleasure to welcome you to this special issue, which collected the best papers form the $1^{\text {st }}$ ACM International Workshop on Semantic Ambient Media Experience (NAMU Series) $S A M E^{\prime} 08$. The first article in the special issue contains a full analysis of the contribution to the workshop, as well as it contains the results of the workshop, which was actually a 'workshop' in form of a creative think-tank instead of simple paper presentations.

\subsection{About the SAME workshop series}

SAME was premiered this year, and is aiming at a series of conferences and workshops for presenting cutting edge research results, case-studies, artistic installations, user-experience studies, and innovations of semantic ambient media technology, content, art, and applications. The workshop aimed at the creation of a think-tank of creative thinkers coming from technology, art, human-computer interaction, and social sciences interested in glimpsing the future of semantic ambient media technology. The aim was to collect multidisciplinary, future oriented submissions that help to develop the 'ambient media

\footnotetext{
A. Lugmayr

Tampere University of Technology, Tampere, Finland

e-mail: lartur@acm.org
}

\section{A. Lugmayr}

LugYmedia Inc., Helenankuja 3 / A 1, FIN-33100 Tampere, Finland

T. Risse $(\bowtie)$

L3S Research Center, Hannover, Germany

e-mail: risse@L3S.de

B. Stockleben

Rundfunk Berlin Brandenburg (RBB), Berlin, Germany

e-mail: Bjoern.Stockleben@rbb-online.de

J. Kaario $\cdot$ K. Laurila

Nokia, Tampere, Finland

J. Kaario

e-mail: Juha.Kaario@nokia.com

K. Laurila

e-mail: Kari.Laurila@nokia.com 
form'. SAME gives especially innovative and visionary scientists a unique opportunity to share their perspectives with others in a distinguished way.

\subsection{Ambient media association (AMEA)}

The workshop organizers are currently establishing the international Ambient Media Association (AMEA) www.ambientmediaassociation.org, which also contains further information and resources about ambient media. The workshop homepage to be found at: http://namu.cs.tut.fi/acmmm2008/same2008/. Any interesting parties are invited to subscribe to our newsletter or see follow-up activities that we are undertaking.

\section{SAME'08 general chairs}

Artur Lugmayr (Tampere Univ. of Techn. \& lugYmedia Inc., Finland)

Thomas Risse (L3S Research Center, Germany)

Bjoern Stockleben (Rundfunk Berlin Brandenburg (RBB), Germany)

Juha Kaario Nokia, Finland)

Kari Laurila (Nokia, Finland)

\section{Papers in this Special issue}

- Semantic Ambient Media: An Introduction

○ Artur Lugmayr, Tampere Univ. of Technology (TUT), Finland

- Thomas Risse, L3S Research Center, Germany

$\circ$ Bjoern Stockleben, RBB, Germany

$\circ$ Juha Kaario, Nokia, Finland

- Kari Laurila, Nokia, Finland

- Towards Environment-to-Environment (E2E) Multimedia Communication Systems

- Vivek Singh, University of California, Irvine, USA

- Hamed Pirsiavash, University of California, Irvine, USA

- Ish Rishabh, University of California, Irvine, USA

○ Ramesh Jain, University of California, Irvine, USA

- Mid-air Display Experiments to Create Novel User Interfaces

○ Ismo Rakkolainen, University of California, USA

- A Framework for Human-Centered Provisioning of Ambient Media Services

- M. Anwar Hossain, University of Ottawa, Canada

o Pradeep K. Atrey, University of Winnipeg, Canada

- Abdulmotaleb El Saddik, University of Ottawa, Canada

- Virtual Assistant: Enhancing Content Acquisition by Eliciting Information from Humans

○ Motoyuki Ozeki, Kyoto University, Japan

○ Shunichi Maeda, Kyoto University, Japan 
○ Kanako Obata, Kyoto University, Japan

- Yuichi Nakamura, Kyoto University, Japan

- Creating Ambient Music Spaces in Real and Virtual Worlds
- Jakob Frank, Vienna University of Technology, Austria
- Thomas Lidy, Vienna University of Technology, Austria
$\circ$ Ewald Peiszer, n/n, Austria
- Ronald Genswaider, n/n, Austria
- Andreas Rauber, Vienna University of Technology, Austria

Acknowledgements We would especially thank our program committee for their value input, namely ShuChing Chen, Andreas Rauber, Mark Billinghurst, Carmen Mac Williams, Heiko Schuldt, Carlos Ramos, Carsten Magerkurth, Ismo Rakkolainen, Jan Nesvadba, Gabriele Kotsis, Jussi Kangasharju, Pablo Cesar, Zhiwen Yu, Tuula Leinonen, Sofia Tsekeridou, Richard Chbeir, Bjorn Landfeldt, and Konstantinos Chorianopoulos.

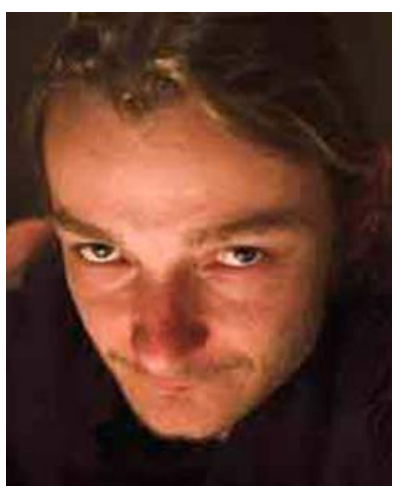

Artur Lugmayr describes himself as a creative thinker and his scientific work is situated between art and science. His vision can be expressed as to create media experiences on future emerging media technology platforms. He will be full professor at the Faculty of Business and Technology Management at the Department of Business Information Management and Logistics at the Tampere Univ. of Technology, Tampere, Finland starting with summer 2009. He is pursuing his second doctorate at the School of Motion Picture, TV and Production Design in Helsinki, Finland. He is the head and founder of the New AMbient MUltimedia (NAMU) research group at the Tampere University of Technology (Finland) which is part of the Finnish Academy Centre of Excellence of Signal Processing from 2006 to 2011. The research group focuses on the development of smart spaces for media. He is currently preparing his second, individually authored, text-book entitled "Ambient Media and Beyond" with Springer-Verlag in 2006. He chaired the ISO/IEC adhoc group "MPEG-21 in broadcasting"; won the NOKIA Award of 2003 with the text book "Digital interactive TV and Metadata" published by Springer-Verlag in 2004; country representative of the Swan Lake Moving Image \& Music Award; project proposal reviewer; invited key-note speaker for conferences; workshop organizer for conferences; reviewer for publications and book chapters; has contributed one book chapter and written over 25 scientific publications. He gained his scientific practical experience in Austria (University Linz, RISC), Finland (Tampere University of Technology, School of Motion Picture, TV, and Production Design) and Greece, where he participated in several research projects. He is the inventor of biomultimedia - integrated human capacity and the MPEG-21 based Digital Broadcast Item Model (DBIM). His passion in private life is to be a notorious digital filmmaker. More about him at http://www.cs.tut.fi/ lartur and on http://namu.cs.tut.fi. 


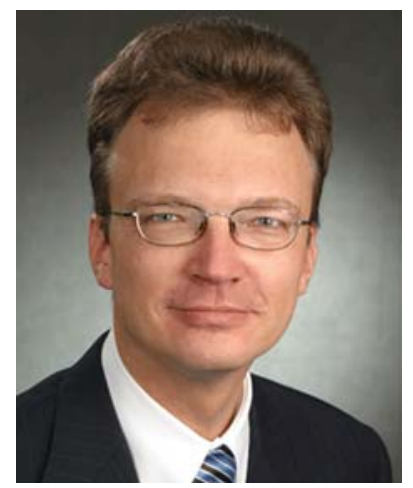

Thomas Risse is the deputy managing director of the L3S Research Center in Hannover. He received a PhD in Computer Science from the Darmstadt University of Technology, Germany in 2006. Before he joined the L3S Research Center in 2007 he lead a research group about intelligent information environments at Fraunhofer IPSI, Darmstadt. He worked in several European and industrial projects. He was the technical director of the European funded integrated project BRICKS, which aim was to build a decentralized infrastructure for distributed digital libraries. Currently he is the coordinator of the FP7 Living Web Archive (LiWA) project. Thomas Risse's research interests are semantic evolution, data management in distributed systems, federated search, and self-organizing systems. He serves regularly as program committee member or project reviewer. He published several papers at the relevant international conferences.

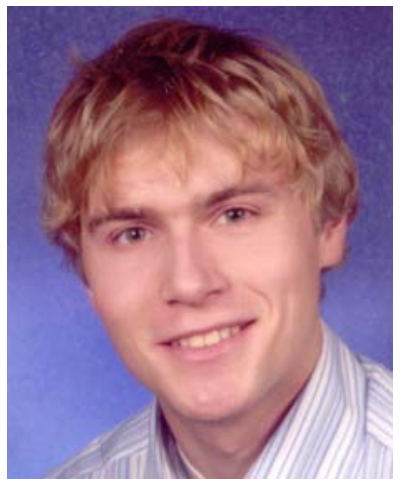

Bjoern Stockleben was awarded his master's degree in Media Sciences, Media Technology and Computer Sciences from Technical University of Brunswick and Brunswick School of Arts in 2003. Since then he has been acting as technical manager at Rundfunk Berlin-Brandenburg Innovation Projects in EC-and ESAfunded research projects such as IST-INSTINCT, IST-ENTHRONE and ARTES-COTV. He is an expert in participative media, interactive service authoring and non-linear AV media. His current research focus is personalized radio services based on MPEG-21 and collaborative video editing. He lectures in media theory at University of Applied Sciences Bremen. 


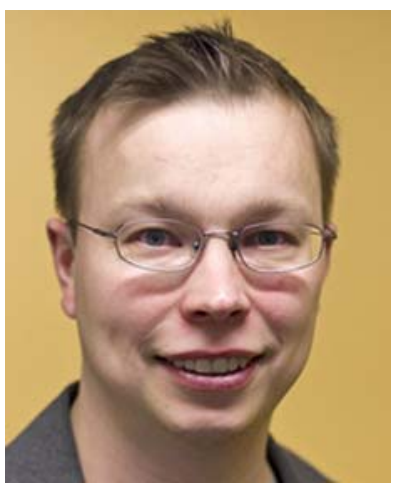

Juha Kaario, MSc, is a Principal Member of Engineering Staff at the Nokia Research Center. He joined Nokia Mobile Phones marketing department in 1995 and moved to Nokia Research in 1997. In Nokia research Center he has worked 10 years as a research manager and senior research manager for several teams including Wearable Computing (1998-2002), Personal Content (2002-2003) and Mobile Games (20032007). Previously he has worked in the University of Tampere (1993-94), in the Technical Research Center of Finland (1992-93) and as a co-owner in a small enterprise (1993-1996). He is one of the originators of the Multi-User Publishing Environment (MUPE) application platform. His interest is in multi-discipline research for personal content, pervasive computing and mobile services. He is currently working in Nokia ecological research team focusing on ethical consumption and social media.

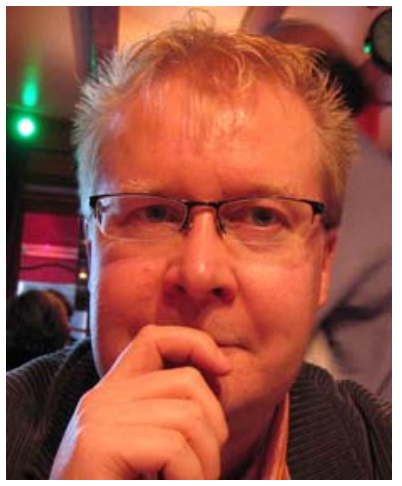

Kari Laurila graduated from Tampere University of Technology, and joined Nokia Research Center (NRC), Tampere, in 1993. First Kari studied automatic speech recognition (ASR) for 8 years, during which time he also finished his doctoral thesis (2000). Kari's team developed noise robust algorithms for speaker-dependent ASR for mobile phones, and later on they developed a small footprint engine for multi-lingual speakerindependent voice control of mobile devices covering tens of languages simultaneously. These research results were successfully transferred to Nokia product programs. In 2001, Kari moved to NRC Japan, and held a general manager position in a highly interdisciplinary team for 2 years. After Japan, Kari jumped back to his 'early roots' and studied advanced electronic gaming. Kari's research program concentrated on motion tracking input devices; wireless game pads and motion bands being the main outcomes. These devices allowed gamers to use their body movements to control gaming characters. In addition, the team carried out research e.g. on near-to-eye displays based on diffractive optics, which devices will allow immersive gaming experience with a very lightweight form factor. At the moment Kari is working with NRC Media lab, and studies personalization and intelligence in the context of social media services. Kari's research team develops four different Internet services which all have strong mobile elements. Kari is author of over 20 conference papers and holds over 10 granted patents. See research.nokia.com/people/kari_laurila/index.html 